\title{
A simple novel device for air sampling by electrokinetic capture
}

\author{
Julian Gordon ${ }^{*}$, Prasanthi Gandhi ${ }^{1}$, Gajendra Shekhawat ${ }^{2}$, Angel Frazier ${ }^{3}$, Jarrad Hampton-Marcell ${ }^{3}$ \\ and Jack A. Gilbert ${ }^{3,4,5,6,7}$
}

\begin{abstract}
Background: A variety of different sampling devices are currently available to acquire air samples for the study of the microbiome of the air. All have a degree of technical complexity that limits deployment. Here, we evaluate the use of a novel device, which has no technical complexity and is easily deployable.

Results: An air-cleaning device powered by electrokinetic propulsion has been adapted to provide a universal method for collecting samples of the aerobiome. Plasma-induced charge in aerosol particles causes propulsion to and capture on a counter-electrode. The flow of ions creates net bulk airflow, with no moving parts. A device and electrode assembly have been re-designed from air-cleaning technology to provide an average air flow of $120 \mathrm{lpm}$. This compares favorably with current air sampling devices based on physical air pumping. Capture efficiency was determined by comparison with a $0.4 \mu \mathrm{m}$ polycarbonate reference filter, using fluorescent latex particles in a controlled environment chamber. Performance was compared with the same reference filter method in field studies in three different environments. For 23 common fungal species by quantitative polymerase chain reaction (qPCR), there was $100 \%$ sensitivity and apparent specificity of $87 \%$, with the reference filter taken as "gold standard." Further, bacterial analysis of 165 RNA by amplicon sequencing showed equivalent community structure captured by the electrokinetic device and the reference filter. Unlike other current air sampling methods, capture of particles is determined by charge and so is not controlled by particle mass. We analyzed particle sizes captured from air, without regard to specific analyte by atomic force microscopy: particles at least as low as $100 \mathrm{nM}$ could be captured from ambient air.

Conclusions: This work introduces a very simple plug-and-play device that can sample air at a high-volume flow rate with no moving parts and collect particles down to the sub-micron range. The performance of the device is substantially equivalent to capture by pumping through a filter for microbiome analysis by quantitative PCR and amplicon sequencing.
\end{abstract}

Keywords: Atomic force microscopy, Reverse transcriptase PCR, Air sampling, Field study, Aerosol, Nanoparticles, Aerobiome, Amplicon sequencing, Bacteria, Molds

\section{Background}

Understanding of the microbiology of air, the aerobiome, is an emerging field of discovery. High-throughput sequencing methods are being used to explore the spatiotemporal distribution of bacterial and fungal populations [1-10]. A variety of sampling methods have been used for studying the air microbiome [3, 11-14]. A variety of different sampling devices are currently available to acquire air samples of microbial and viral particles [15].

\footnotetext{
* Correspondence: jgordon@inspirotec.com

${ }^{1}$ Inspirotec LLC, 3307 Meadow Lane, Glenview, IL 60025, USA

Full list of author information is available at the end of the article
}

These technologies include filters, impingers, impactors, and wet or dry cyclones. The underlying principle of impactors, impingers, and cyclones is the use of an abrupt change in direction of airflow so that aerosol particles will continue on to a surface by virtue of their momentum. Filters are microporous membranes, impingers capture on to the surface of a nutrient agar plate for subsequent colony counts, and impactors capture on a solid surface for subsequent elution, as do dry cyclones. Wet cyclones capture by vortexing into a liquid phase. Aerosol particles may also be separated into size classes with multi-stage devices. For existing devices, capture efficiency falls off rapidly with particle size and there is 
considerable variability in performance [16-18]. All of these devices require pumping against some resistance. Different apparent microbial communities were found from the use of different air sampling techniques [11, 13]. There is thus a need in aerobiome analysis for a sampling procedure that does not bias the measured biodiversity. Here, we introduce the use of a very simple device for collection of samples and show equivalence to a reference method using filtration. In addition, a variety of air sampling methods have been applied to the airborne transmission of disease [19-30].

Brown first described the principle of ionic propulsion in US patents [31,32]. A corona wire is subject to a high voltage, creating plasma that imparts charge on particles in the vicinity. The charged particles are then propelled by the voltage gradient to electrodes at an opposing potential. The net flow of charged particles imparts forward momentum on the surrounding medium. The result is a net airflow with no moving parts. This principle has been used in commercial air-cleaning devices [33]. Custis et al. [34] used such an air-cleaning device for collecting dust from the air for measuring allergens. We have developed a mini-scale device using the same principle with optimized airflow and an electrode cartridge that is optimized for sample collection (Inspirotec Sampler). We have demonstrated its use for detection of allergens by immunoassay [35, 36] and viruses by quantitative PCR [37]. The device is simple to operate, compact, and can be placed unobtrusively in any environment. Here, we compare performance with a filter reference method for analysis of the aerobiome.

\section{Results}

For the purpose of this study, three environments were selected for side-by-side comparison of the Inspirotec Sampler, with an air filter as a reference device. The environments were a clean bathroom, a basement room with an exposed sump drain, and a hay storage room in a large equestrian facility.

\section{Mold spores}

Mold spores are ubiquitous in the environment but vary according to temperature, humidity, season, and other environmental conditions. Table 1 shows the results of $24-\mathrm{h}$ samples in the three locations. The Inspirotec Sampler values have not been corrected for capture efficiency (approximately $20 \%$, see "Methods" section). If this

Table 1 Mold spores in three locations

\begin{tabular}{|c|c|c|c|c|c|c|}
\hline \multirow{3}{*}{ Mold species } & \multicolumn{6}{|c|}{ Spore equivalents (units per 10,000 liters of air) } \\
\hline & \multicolumn{2}{|c|}{ Bathroom } & \multicolumn{2}{|c|}{ Basement } & \multicolumn{2}{|c|}{ Stable } \\
\hline & A & B & A & B & A & B \\
\hline Acremonium strictum & $<0.4$ & $<3$ & $<0.5$ & $<3$ & 38.00 & 50.93 \\
\hline Alternaria alternata & $<0.5$ & $<3$ & 1.77 & 3.70 & 28.83 & 78.70 \\
\hline Aspergillus flavus & $<2$ & $<14$ & 5.24 & 35.19 & 4324 & 9259 \\
\hline Aspergillus fumigatus & 0.46 & $<1$ & 1.57 & 46.30 & 8713 & 14815 \\
\hline Aspergillus niger & $<0.1$ & $<0.9$ & $<0.2$ & $<0.9$ & 64.86 & 208.33 \\
\hline Aspergillus ochraceus & 1.64 & 5.09 & 41.93 & 2500 & 0.39 & $<1.4$ \\
\hline Aspergillus sydowii & $<11$ & $<90$ & $<14$ & $<90$ & 1638 & $<33$ \\
\hline Aspergillus ustus & $<0.3$ & $<2$ & $<0.3$ & $<2$ & $<1$ & $<1$ \\
\hline Aspergillus versicolor & $<4$ & $<33$ & 21.62 & 342.59 & 1074 & 2962 \\
\hline Chaetomium globosum & $<0.1$ & $<0.9$ & $<0.1$ & $<0.9$ & 7.47 & 0.93 \\
\hline Cladosporium cladosporioides & 1.24 & 0.93 & 39.96 & 370 & 373 & 648 \\
\hline Eurotium amstelodami & 3.73 & $<0.5$ & 1973 & 458 & 262 & 555 \\
\hline Memnoniella echinata & $<0.1$ & $<0.5$ & $<0.1$ & $<0.5$ & $<0.2$ & $<0.5$ \\
\hline Paecilomyces variotii & $<0.1$ & $<0.5$ & 3.87 & 16.20 & 6027 & 10185 \\
\hline Penicillium aurantiogriseum & $<0.7$ & $<6$ & $<0.9$ & $<6$ & 222 & 180 \\
\hline Penicillium brevicompactum & 20.70 & 92.59 & 19.85 & 375 & 1356 & 925 \\
\hline Penicillium chrysogenum (Type 2) & $<0.2$ & $<3$ & 1.57 & 37.96 & 1389 & 2500 \\
\hline Penicillium purpurogenum & $<0.1$ & $<1.4$ & $<0.3$ & $<1.4$ & $<0.7$ & $<0.5$ \\
\hline Penicillium variabile & $<1$ & $<9$ & $<1$ & $<9$ & 0.98 & $<3$ \\
\hline Scopulariopsis brevicaulis & 0.13 & $<0.9$ & $<0.2$ & $<0.9$ & 177 & 338 \\
\hline Stachybotrys chartarum & $<0.7$ & $<6$ & 1.83 & $<6$ & 3.93 & 12.04 \\
\hline Trichoderma viride & $<0.1$ & $<0.5$ & 0.33 & $<0.6$ & 27.52 & 60.19 \\
\hline Ulocladium botrytis & $<0.2$ & $<1.4$ & 1.31 & 3.24 & 18.15 & 15.28 \\
\hline
\end{tabular}

A Inspirotec Sampler, B filter. Spore equivalent values were determined by multiplex qPCR (see "Methods" section). Green shading: detectable by both methods; yellow: detectable by Inspirotec Sampler only; no shading: below the limit of detection of the qPCR 
correction were applied, the values would all be consistent within the standard deviations achievable by the quantitative polymerase chain reaction (qPCR). Those cases where the species was detected by both methods are indicated by green shading. In no instance was a species detectable by the filter and not detectable by the Inspirotec Sampler. In eight instances, the Inspirotec Sampler detected a species that was not detected by the filter, indicated by yellow shading in Table 1. By this criterion, if the filter is considered a gold standard, the sensitivity is $100 \%$ and the specificity is $87 \%$. However, these are likely to be true positives since the Inspirotec Sampler is sampling a larger volume of air in a given time. To address this concern, we examined the accumulation rate for Eurotium amstelodami on both filters and the Inspirotec Sampler (Fig. 1). This shows that the Inspirotec Sampler processed both a larger volume, and correspondingly, a larger quantity of spore equivalents were captured, when compared to the filter. As with Table 1, these numbers have not been corrected for capture efficiency. It is not clear why the quantity of spore equivalents captured appears to peak at $6 \mathrm{~h}$ for both filter sampling and Inspirotec Sampler. Nevertheless, this illustrates the advantage of the high sampling volume of the Inspirotec Sampler. This advantage is compounded by the Inspirotec Sampler's easier logistical set-up and silent performance.

\section{Bacterial diversity}

Timed samples were run in the basement environment with the same schedule as in Fig. 1. Bacterial 16S rRNA amplicon sequencing generated a total of $1,294,310$ sequences from 22 samples. When rarified to 9800 sequences per sample, 385,076 operational taxonomic units (OTUs; $97 \%$ identity) were identified. No significant difference in microbial community structure was observed between the Inspirotec Samplers and the reference method with the use of the R Project for Statistical Computing freeware (weighted or unweighted UniFrac distance ADONIS, $p>0.05, R=0.06$ ). False-discovery rate (FDR) and Bonferronicorrected $p$ values showed no significant differences in OTU frequencies between platforms. The genus-level community profile generated by both technologies comprised predominantly Acinetobacter, Gordonia, Methylobacterium, and Pseudomonas (Fig. 2). Differences in abundances in Fig. 2 are therefore not significant.

Interestingly, 180 min produced a signal highly similar to the time zero (blank) suggesting that this time frame was insufficient to generate enough biomass for the detection threshold of the amplicon sequencing technology (Fig. 2). However, by $360 \mathrm{~min}$, the community profiles were significantly different from time zero. Reagent-based contamination is known to be an issue [38] and explains the detected signal for blank and $180 \mathrm{~min}$. The

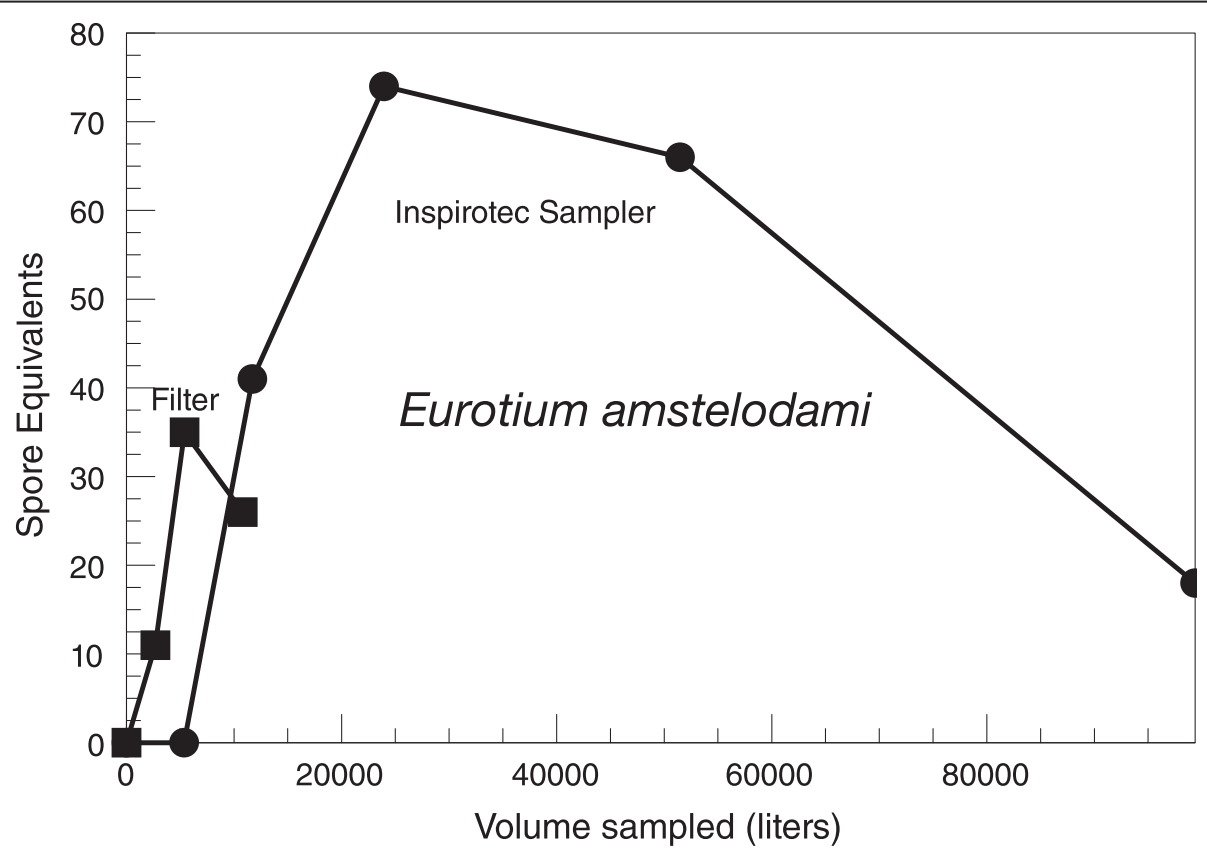

Fig. 1 Time course for spore collection. Air samples were taken at 0, 45, 90, 180, 360, and 720 min for the Inspirotec Sampler and at 0, 180, 360, and $720 \mathrm{~min}$ for the filters in the stable of Table 1. Volume sampled is computed from the individual Inspirotec Sampler flow rates and from the $15 \mathrm{lpm}$ setting for the filters. Zero time samples were placed in the respective device, power was not turned on, and they were otherwise treated identically to the timed samples 


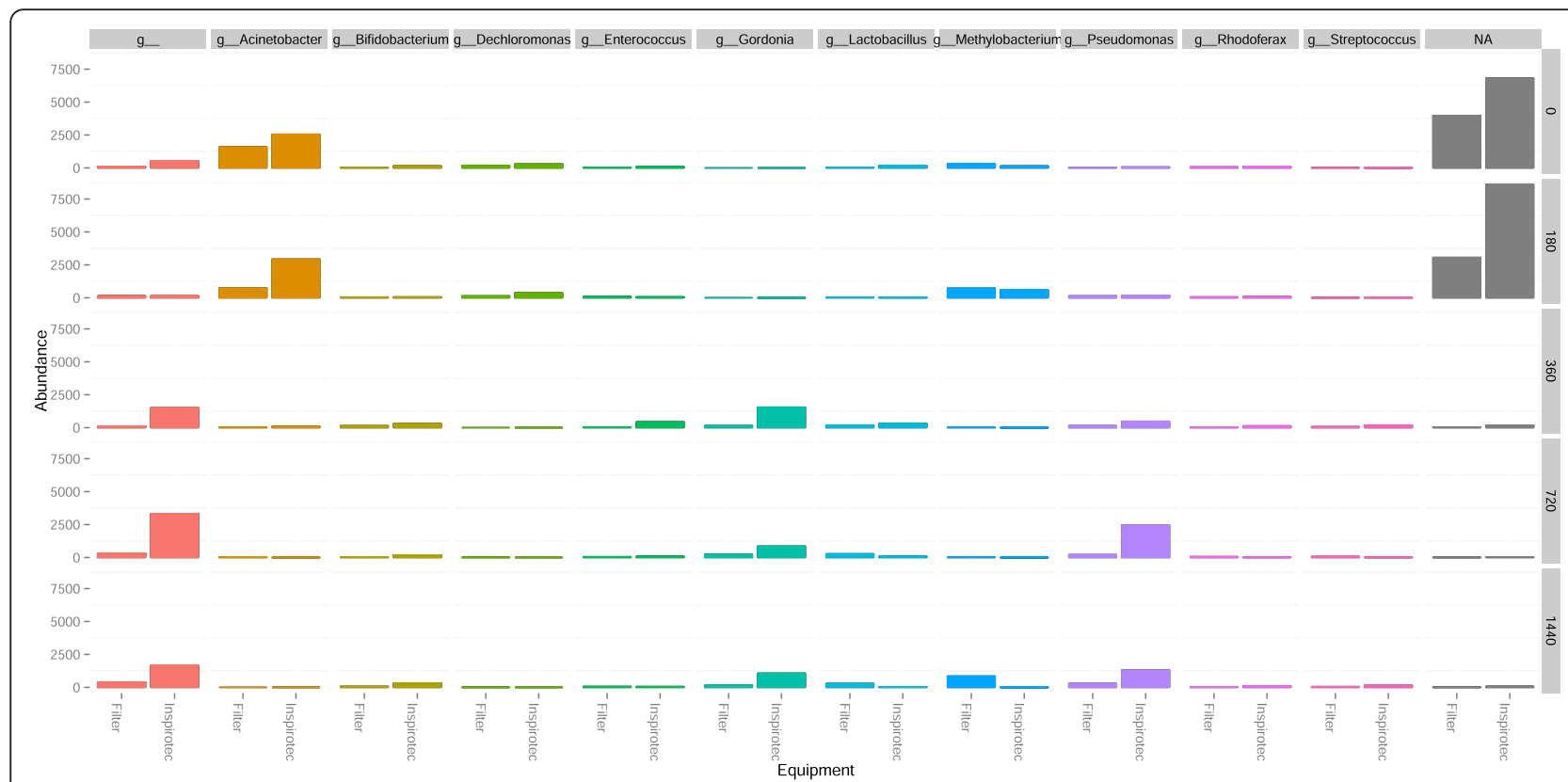

Fig 2 Relative abundance of bacterial genera as a function of sampling time. Samples were collected following the time protocol of Fig. 1 in the basement location of Table 1. The top 25 sequences were selected from the OTU table, and relative abundance of bacterial genera was plotted across consecutive time points between samplers as described in the "Methods" section. Zero time samples were as in Fig. 1

significance of the similarity between microbial profiles generated by the filter and Inspirotec Sampler technologies at each time point was assessed using Procrustes analysis including the left and right electrode (technical replicates) of the Inspirotec Sampler as well as the pumpdriven filter. Over the course of time, there was no significant difference between either technical replicate or the air filter, despite greater variability between samplers at the starting zero time (Monte Carlo, $p>0.05$ ) (Fig. 3).

\section{Particle size and capture}

A prediction of the method of using ionic propulsion to capture the charge particles is that the capture should be independent of particle size of mass, unlike current aerodynamic-based sampling systems. The location of capture is dependent on the force vectors determined by the voltage gradient. Mass may affect particle acceleration and velocity, but the final capture location is determined by a potential well. We therefore explored

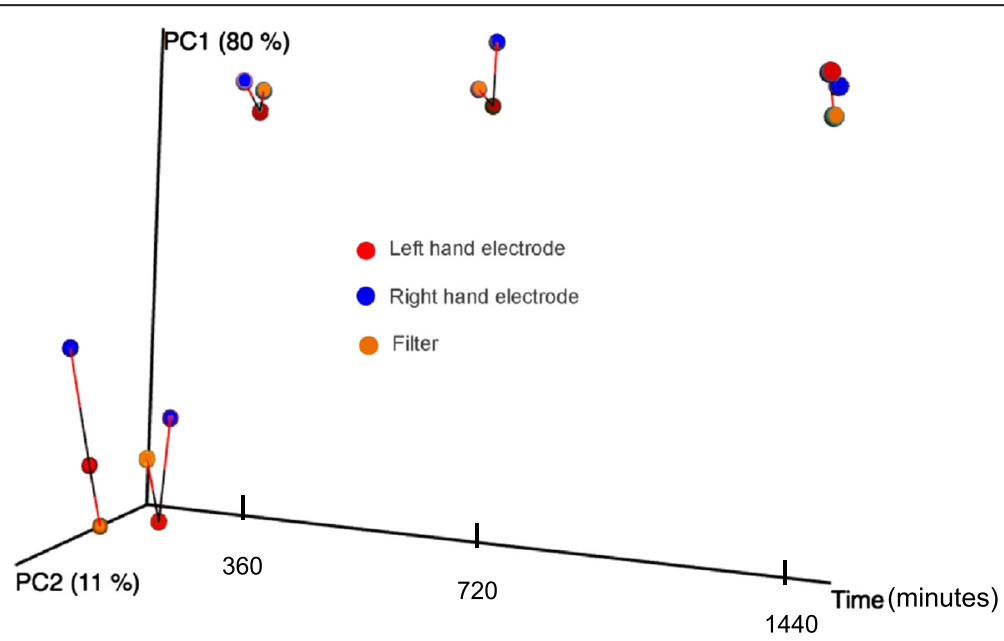

Fig 3 Procrustes analysis of bacterial community structure as a function of sampling time. A principal coordinate analysis (PCoA) was generated for each of the replicate electrodes and the filter samples. CV1 and CV2 are the first two dimensions of variance that describe the most variance in the multidimensional structure of this population, represented by the percentages on the axes. UniFrac distances from each PCoA were comparatively superimposed by collection time 
sample capture with a random sample of air (bathroom of Table 1) and examined the size distribution of captured particles by atomic force microscopy. Particles down to the nanometer range were captured (Fig. 4), as demonstrated using a visual representation of particle size density (Fig. 4a), as well as a size distribution curve, with a significant fraction trailing into the lower range (Fig. 4b).

The Inspirotec Sampler was run in the bathroom for 24-h (Table 1) and scanned (see "Methods" section). The inset shows the lower end of the distribution curve and captured particles extending down into the 500-nm range and below. The sampler is thus able to capture particles going down to very low sizes and in the range that will penetrate the lungs and cause symptoms. This illustrates the range of sizes of not-identified aerosol particles that are captured.

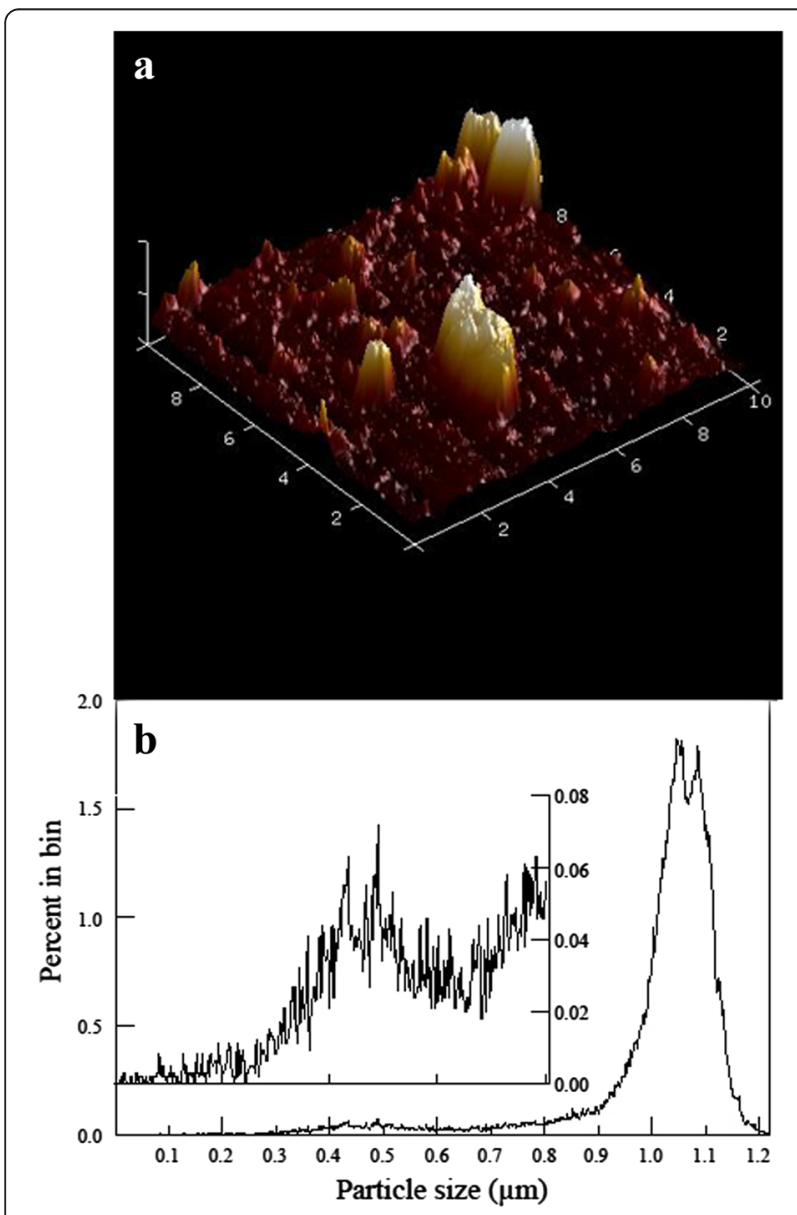

Fig 4 Atomic force microscopy of biomass captured. The Inspirotec Sampler was run 6 days in the bathroom (Table 1) and scanned (see "Methods" section). a False color 3D representation of a 10× $10 \mu \mathrm{m}$ square. Height above the plane is in the same micrometer scale. b Particle size distribution analysis of same data. Size distribution in 512 bins and percent of particles in each bin plotted. Inset: 0-0.8 $\mu \mathrm{m}$ range shown on $\times 10$ expanded scale

\section{Conclusion}

We have demonstrated the applicability of an electrokinetic air sampler for the molecular detection of microorganisms in air. All procedures are of wide applicability to any measurements in the aerobiome. This technology is easily deployed as it can be plugged into any electrical socket, silent, has low visual impact, and so could be readily applied to indoor settings for identifying and tracking emerging pandemics. The device performance was comparable to or exceeded that of the reference method.

\section{Discussion}

The device is inexpensive and requires no technical skill to operate, compared with any other competing technology. Both SARS and MERS [39, 40] epidemics may be traced back to human-animal interfaces, and early deployment in such emerging pandemics would facilitate the tracing of early stages and subsequent routes of transmission. In a separate study [37], we showed the capability of capturing Venezuelan equine encaphilitis virus in a controlled environment chamber at the US Army Edgewood Chemical Biological Center with aerosol particles down to $1 \mu \mathrm{m}$. The viruses had been inactivated by gamma irradiation. The result was that a large proportion of the original virions had RNA that was not amplifiable, so the capture efficiency was apparently very low based on the original virus titer. However, analysis by digital PCR using the Poisson distribution at low amplicon concentrations showed that the capture efficiency was in the range of $20-40 \%$ for these articles. Here, the performance exceeded that of the reference method using a microporous filter and showed ability to detect mold spores using EPA-accepted PCR technology [41]. Of the species for which primers and probes were used in the qPCR, Acremonium strictum, Alternaria alternata, Aspergillus flavus, Aspergillus fumigatus, Aspergillus niger, Aspergillus ochraceus, Aspergillus sydowii, Aspergillus ustus, Aspergillus versicolor, Chaetomium globosum, Cladosporium cladosporioides, Eurotium amstelodami, Memnoniella echinata, Paecilomyces variotii, Penicillium aurantiogriseum, Penicillium brevicompactum, Penicillium chrysogenum (type 2), Penicillium purpurogenum, Penicillium variabile, Scopulariopsis brevicaulis, Stachybotrys chartarum, Trichoderma viride, Ulocladium botrytis, all but Aspergillus ustus, Memnoniella echinata, and Penicillium variabile were detectable as spores over the three locations tested.

Another feature of the electrokinetic propulsion is the ability to capture and measure particles down into the nanoparticle range. Particles generated from respiratory activities in the range of 0.05 to $500 \mu \mathrm{m}$ are associated with infection [42]. Most commonly used air sampling devices have a cut-off at about $1 \mu \mathrm{m}$ [15]. Allergens may extend down to a size range that has been missed by 
current sampling technology [43], and there is evidence that bacterial endotoxin, which exacerbates the effect of allergens, may exist in size ranges below the size of bacteria [44]. The device described in this publication will have the capability of extending the size range of particles that can be collected from the aerobiome.

Fahlgren et al. [13] found that the diversity of microbial communities captured by different samplers in external environments in Norway and Sweden were similar, whereas Hoisington et al. [11] have found significant inconsistencies between different sampler types at locations within a US retail store. In neither case was consideration made to the time of run needed to resolve reagent background. We showed that a minimum of $6 \mathrm{~h}$ sampling was required regardless of the method. We demonstrate the application of ionic propulsion technology to capture a wider range of particle sizes than with traditional air filter sampling, with no significant bias in fungal and bacterial community recovery.

\section{Methods}

Inspirotec Samplers and accompanying electrode cartridges were provided by Inspirotec LLC (Glenview, IL). A commercial air cleaner was modified to achieve a unidirectional flow. The disposable capture cartridges were designed to optimize capture of aerosol particles and for easy release into extraction tubes. They were made by 3D printing at Exact Prototyping, Joliet, IL, and stainless steel electrode strips by Lakeshore Cutting Solutions, Zeeland, MI. Electrodes were finished by Able Electropolishing, Chicago, IL. Cartridges were washed with $70 \%$ isopropanol and air dried, and electrodes were washed with isopropanol and dried in a vacuum oven for $30 \mathrm{~min}$ at $180{ }^{\circ} \mathrm{C}$. Assembled cartridges and electrodes were heatsealed into polyethylene bags until use. Once the electrodes have been released, they cannot be re-used. There is no potentially non-sterile surface that physically contacts the electrodes between removal from the bag and release into the collection tube. An updated version of the Inspirotec Sampler has a block of honeycomb-structured $\mathrm{MnO}_{2}$ catalyst covering the outlet. This modification removes traces of ozone from the effluent air but does not affect performance. Samplers and cartridges can be purchased by sending an email to the senior author with heading "research request." The sampler will have a lower cost than any alternative system.

Flow rates were measured with a hot wire anemometer by averaging measured flow velocities across the width of a duct placed over the outlet [45]. Individual samplers' flow rates varied by $130 \pm 13 \mathrm{lpm}$. Capture efficiency (determined by AlburtyLabs, Inc., Drexel, MO) as judged by capture of $1 \mu \mathrm{m}$ Fluoresbrite ${ }^{\circ}$ YG carboxylate microspheres (Polysciences, Inc., Warrington, PA) in a controlled environment chamber, compared with capture by a reference sampler consisting of a $0.22-\mu \mathrm{M}$ polycarbonate filter, was $(23 \pm 5) \%$ based on 16 determinations. Fluorescence of captured microspheres was with a Turner Quantech fluorometer. The reference samplers were run at $14 \mathrm{lpm}$. Thus, the capture efficiency is more than compensated by the higher volumes of air sampled.

Following their standard isolation procedure, captured mold spores were determined by qPCR for the 23 most common mold species by EMLab P\&K, Marlton, NJ. Primers and probes and amplification conditions used are in [41]. Electrodes were released into $15 \mathrm{ml}$ Falcon tubes and shipped overnight for analysis. They were extracted by vortex mixing intermittently over $10 \mathrm{~min}$ with $0.05 \%$ Tween 20 , and spores were centrifuged down and extracted by bead-beating [46]. Results were computed as spore equivalents [46-49]. These publications show that standard deviations of spore equivalent counts may be \pm 1 $\log$ or more.

Amplicon sequencing: each cartridge holds two electrodes. Left and right electrodes were processed separately, and so were effective duplicates. Individual electrodes were placed into sterile $15-\mathrm{ml}$ conical tubes with $1 \mathrm{ml}$ of sterile water. Samples were extracted for $1 \mathrm{~min}$ on a Vortex Genie (MO BIO Laboratories, Inc., Carlsbad, CA). Their standard PowerSoil extraction was performed according to the manufacturer's suggested protocol with the addition of a 20-min incubation at $65{ }^{\circ} \mathrm{C}$ after addition of solution $\mathrm{C} 1$, as suggested by the Earth Microbiome Project. Genomic DNA was amplified using the Earth Microbiome Project barcoded primer set, adapted for MiSeq (Illumina Inc., San Diego, CA) by adding nine extra bases in the adapter region of the forward amplification primer that support paired-end sequencing. The V4 region of the 16S rRNA gene (515F-806R) was amplified with region-specific primers that included the Illumina flow cell adapter sequences. The reverse amplification primer also contained a 12-base barcode sequence that supports pooling of up to 2167 different samples in each lane. Each 25- $\mu \mathrm{l}$ PCR reaction contains $12 \mu \mathrm{l}$ of MO BIO PCR water (certified DNA-free), $10 \mu \mathrm{l}$ of 5 Prime HotMasterMix ( $5 \mu \mathrm{M}$ concentration), $1 \mu \mathrm{l}$ of forward primer ( $5 \mu \mathrm{M}$ concentration, $200 \mathrm{pM}$ final), $1 \mu \mathrm{l}$ Golay barcode-tagged reverse primer $(5 \mu \mathrm{M}$ concentration, $200 \mathrm{pM}$ final), and $1 \mu \mathrm{l}$ of template DNA. The conditions for PCR were as follows: $94{ }^{\circ} \mathrm{C}$ for $3 \mathrm{~min}$ to denature the DNA, with 35 cycles at $94{ }^{\circ} \mathrm{C}$ for $45 \mathrm{~s}, 50{ }^{\circ} \mathrm{C}$ for $60 \mathrm{~s}$, and $72{ }^{\circ} \mathrm{C}$ for $90 \mathrm{~s}$; and with a final extension of $10 \mathrm{~min}$ at $72{ }^{\circ} \mathrm{C}$ to ensure complete amplification. PCR amplifications were completed in triplicate and then pooled. Following pooling, amplicons were quantified using PicoGreen (Invitrogen) and a plate reader. Once quantified, different volumes of each of the products were pooled into a single tube so that each amplicon was represented equally. This pool was then cleaned 
using the UltraClean ${ }^{\circ}$ PCR Clean-Up Kit (MO BIO) and quantified using Qubit (Invitrogen). Sequencing of the prepared library was performed on the Illumina MiSeq platform, using the sequencing primers and procedures described in the supplementary methods of Caporaso et al. [50].

For the atomic force microscopy, a sampler was run for 6 days in the clean bathroom location of Table 1. It was examined with atomic force microscopy with a Bruker dimension Icon system which has the capability of providing sub-nanometer resolution. Imaging was done in tapping mode with super sharp silicon probes. Results were analyzed with the Bruker analysis software.

\section{Availability of supporting data}

All sequence data will be made available through FigShare, http://dx.doi.org/10.6084/m9.figshare.1603492

\section{Competing interests}

Julian Gordon and Prasanthi Gandhi are co-founders and co-owners of Inspirotec LLC and plan to commercialize the Inspirotec Sampler.

\section{Authors' contributions}

JG contributed to experimental design, performed the air sampling and mold spore data reduction, and had primary responsibility for drafting the manuscript. PG contributed to the experimental design and reviewing of the manuscript. GS performed the atomic force microscopy and interpretation of the results therefrom. AF performed the PCR and amplicon analysis and wrote that part of the methods section. JH-M was responsible for the PCR and amplicon analysis experimental design and data reduction and contributed to the manuscript writing. JAG contributed to the experimental design and manuscript review and writing. All authors read and approved the final manuscript.

\section{Acknowledgements}

This work was partly supported by Breakout Labs, a program of the Thiel Foundation, and partly from personal funds from Julian Gordon and Prasanthi Gandhi. The authors are grateful to MS Diana Schnell for making the equestrian facility available for this study. This work was supported in part by the US Dept. of Energy under Contract DE-AC02-06CH11357.

\section{Author details \\ ${ }^{1}$ Inspirotec LLC, 3307 Meadow Lane, Glenview, IL 60025, USA. ²Department of Materials Science and Engineering, McCormick School of Engineering and Applied Science, Northwestern University, 2220 Campus Drive, \#2036, Evanston, IL 60208, USA. ${ }^{3}$ Genomic and Systems Biology, Bioscience Division, Argonne National Laboratory, 9700 South Cass Avenue, Argonne, IL 60439, USA. ${ }^{4}$ Department of Ecology and Evolution, University of Chicago, $1101 \mathrm{E}$ 57th Street, Chicago, IL 60637, USA. ${ }^{5}$ Department of Surgery, University of Chicago, 5841 South Maryland Avenue, MC 5029, Chicago, IL 60637, USA. ${ }^{6}$ Marine Biological Laboratory, 7 MBL Street, Woods Hole, MA 02543, USA. ${ }^{7}$ College of Environmental and Resource Sciences, Zhejiang University, Hangzhou 310058, China.}

Received: 28 May 2015 Accepted: 2 December 2015 Published online: 27 December 2015

\section{References}

1. Bowers RM, McCubbin IB, Hallar AG, Fierer N. Seasonal variability in airborne bacterial communities at a high-elevation site. Atmos Environ. 2012;50:41-9.

2. Bowers RM, McLetchie S, Knight R, Fierer N. Spatial variability in airborne bacterial communities across land-use types and their relationship to the bacterial communities of potential source environments. ISME J. 2011;5(4):601-12.
3. Bowers RM, Sullivan AP, Costello EK, Collett JL, Knight R and Fierer M. Sources of bacteria in outdoor air across cities in the Midwestern United States. Appl Environ Microbiol. 2011;77(18):6350-6.

4. DeLeon-Rodriguez N, Lathern TL, Rodriguez LM, Barazesh JM, Anderson BE, Ziemba LD, et al. Microbiome of the upper troposphere: species composition and prevalence, effects of tropical storms, and atmospheric implications. Proc Natl Acad Sci U S A. 2013;110(7):2575-80.

5. Woo AC, Brar MS, Chan YK, Lau MCY, Leung FCC, Scott JA, et al. Temporal variation in airborne microbial populations and microbially-derived allergens in a tropical urban landscape. Atmos Environ. 2013;74:291-300.

6. Kembel SW, Jones E, Kline J, Northcult D, Stenson J, Wornack AM, et al. Architectural design influences the diversity and structure of the built environment microbiome. ISME J. 2012;6(8):1469-79.

7. Rangaswamy BE, Francis F, Prakash KK, Manjunath NS. Variability in airborne bacterial and fungal population in the tertiary health care centre. Aerobiologia. 2013;29(4):473-9.

8. Shogan BD, Smith DP, Packman Al, Kelley ST, Landon EM, Banghar S, et al. The Hospital Microbiome Project: meeting report for the 2nd Hospital Microbiome Project, Chicago, USA, January 15th, 2013. Stand Genomic Sci. 2013;8(3):571-9.

9. Caporaso JG, Lauber CL, Wallers WA, Berg-lyons D, Huntley J, Fierer N, et al. Ultra-high-throughput microbial community analysis on the Illumina HiSeq and MiSeq platforms. ISME J. 2012;6(8):1621-4.

10. Lax S, Smith DP, Hampton-Marcell J, Owens SM, Handley KM, Scott NM, et al. Longitudinal analysis of microbial interaction between humans and the indoor environment. Science. 2014;345(6200):1048-52.

11. Hoisington AJ, Maestre JP, King MD, Siegel JA, Kinney KA. Impact of sampler selection on the characterization of the indoor microbiome via high-throughput sequencing. Build Environ. 2014;80:274-82.

12. Frohlich-Nowoisky J, Maestre JP, King MD, Siegel JA, Kinney KA. Diversity and seasonal dynamics of airborne archaea. Biogeosciences. 2014;11(21): 6067-79.

13. Fahlgren C, Bratbak G, Sandaa RA, Thyrhaug R, Zweifel UL. Diversity of airborne bacteria in samples collected using different devices for aerosol collection. Aerobiologia. 2011;27(2):107-20.

14. Eduard W, Heederik D, Duchaine C, Green BJ. Bioaerosol exposure assessment in the workplace: the past, present and recent advances. J Environ Monit. 2012;14(2):334-9.

15. Ruzer LS, Harley NH. Aerosols handbook : measurement, dosimetry, and health effects (CRC Press, Boca Raton, FL) 2nd ed; (2013) pp 318-321.

16. Kesavan J, Schepers D, MCFarland AR. Sampling and retention efficiencies of batch-type liquid-based bioaerosol samplers. Aerosol Sci Technol. 2010:44(10):817-29.

17. Kesavan J, Bottiger JR, McFarland AR. Bioaerosol concentrator performance: comparative tests with viable and with solid and liquid nonviable particles. J Appl Microbiol. 2008;104(1):285-95.

18. Dybwad M, Skogan G, Blatny JM. Comparative testing and evaluation of nine different air samplers: end-to-end sampling efficiencies as specific performance measurements for bioaerosol applications. Aerosol Sci Technol. 2014;48(3):282-95

19. Lindsley WG, Blachere FM, Davis KA, Pearce TA, Fisher MA, Khakoo R, et al. Distribution of airborne influenza virus and respiratory syncytial virus in an urgent care medical clinic. Clin Infect Dis. 2010;50(5):693-8.

20. Yang W, Elankumaran S, Marr LC. Concentrations and size distributions of airborne influenza A viruses measured indoors at a health centre, a day-care centre and on aeroplanes. J R Soc Interface. 2011;8(61):1176-84

21. Gehanno JF, Louvel A, Nouvellon M, Caillard JF, Pestel-Caron M. Aerial dispersal of meticillin-resistant Staphylococcus aureus in hospital rooms by infected or colonised patients. J Hosp Infect. 2009;71(3):256-62.

22. Shiomori T, Miyamoto H, Makishima K. Significance of airborne transmission of methicillin-resistant Staphylococcus aureus in an otolaryngology-head and neck surgery unit. Arch Otolaryngol Head Neck Surg. 2001;127(6):644-8.

23. Shiomori T, Miyamoto H, Makashima K, Yoshida M, Fujiyoshi T, Udaka T, et al. Evaluation of bedmaking-related airborne and surface methicillin-resistant Staphylococcus aureus contamination. J Hosp Infect. 2002;50(1):30-5.

24. Chen P-S, Li C-S. Concentration profiles of airborne Mycobacterium tuberculosis in a hospital. Aerosol Sci Technol. 2008;42(3):194-200.

25. Alberti C, Boukline A, Ribaud P, Lacroix C, Rousselot P, Leblanc T, et al. Relationship between environmental fungal contamination and the incidence of invasive aspergillosis in haematology patients. J Hosp Infect. 2001;48(3):198-206. 
26. Curtis L, Cali S, Conroy L, Baker K, Ou CH, Hershow R, et al. Aspergillus surveillance project at a large tertiary-care hospital. J Hosp Infect. 2005;59(3): 188-96.

27. Fournel I, Soutour M, Lafon I, Sixt N, L'Ollivier C, Dalle F, et al. Airborne Aspergillus contamination during hospital construction works: efficacy of protective measures. Am J Infect Control. 2010;38(3):189-94.

28. Morrison J, Yang C, Lin KT, Haugland RA, Neely AN, Vesper SJ. Monitoring Aspergillus species by quantitative PCR during construction of a multistorey hospital building. J Hosp Infect. 2004;57(1):85-7.

29. Ortiz G, Yague G, Segovia M, Catalan V. A study of air microbe levels in different areas of a hospital. Curr Microbiol. 2009;59(1):53-8.

30. Goodley JM, Clayton YM, Hay RJ. Environmental sampling for aspergilli during building construction on a hospital site. J Hosp Infect. 1994;26(1):27-35.

31. Brown TT. Electrokinetic apparatus. "Electrokinetic Apparatus." U.S. Patent $2,949,550,1960$

32. Brown TT. Fluid flow control system. "Fluid Flow Control System". U.S. Patent 3,518,462, 1970.

33. Hubar JS, Pelon W, Strother EA, Sicard FS. Reducing Staphylococcus aureus bacterial counts in a dental clinic using an lonic Breeze air purifier: a preliminary study. Gen Dent. 2009:57(3):226-9.

34. Custis NJ, Woodfolk JA, Vaughan JW, Platts-Mills TAE. Quantitative measurement of airborne allergens from dust mites, dogs, and cats using an ion-charging device. Clin Exp Allergy. 2003:33(7):986-91.

35. Gordon J, Gandhi P, Alburty D, Murowchick P. Evaluation of a compact ionic capture device for airborne allergens with the use of a controlled environmental chamber. J Allergy Clin Immunol. 2013;131(2):AB76-AB76.

36. Gordon J, Gandhi P, Shekhawat G, Bailey A, Phipatanakul W. Evaluation of a compact ionic capture device for airborne allergens in inner city schools. J Allergy Clin Immunol. 2014;133(2):AB187-AB187.

37. Gordon J, Gandhi P, Sutton T, Pongrance K, Bottiger J. (Evaluation of an ion capture device for determination of aerosolized Venezuelan equine encaphailitis virus and a novel method for absolute particle count determination. American Association for Aerosol Research. 2013. Available at: http://www. eposters.net/pdfs/evaluation-of-an-ion-capture-method-for-determination-ofaerosolized-venezuelan-equine-encaphalitis.pdf. Accessed December 12, 2015

38. Salter SJ, MJ, Turek EM, Calus ST, Cookson WA, Moffat MF, Turner P, et al. Reagent and laboratory contamination can critically impact sequence-based microbiome analyses. BMC Biol. 2014; 1- 12.

39. Kupferschmidt K. EMERGING DISEASES Researchers Scramble to Understand Camel Connection to MERS. Science. 2013:341(6147):702-702.

40. Chan PKS, Chan MCW. Tracing the SARS-coronavirus. J Thorac Dis. 2013:5:S118-21.

41. Haugland R, Vesper S. Method of identifying and quantifying specific fungi and bacteria. "Method of Identifying and Quantifying Specific Fungi and Bacteria". U.S. Patent 6,387,652, 2002

42. Gralton J, Tovey E, McLaws ML, Rawlinson WD. The role of particle size in aerosolised pathogen transmission: a review. J Infect. 2011;62(1):1-13.

43. Custovic A, Woodcock H, Craven M, Hasall R, Hadley E, Simpson A, et al. Dust mite allergens are carried on not only large particles. Pediatr Allergy Immunol. 1999;10(4):258-60.

44. Kujundzic E, Hernandez M, Miller SL. Particle size distributions and concentrations of airborne endotoxin using novel collection methods in homes during the winter and summer seasons. Indoor Air. 2006;16(3):216-26.

45. Anonymous (Traversing a duct to determine average air velocity or volume. Application note TSI 106. TSI Incorporated. 2013. Available at http://www.tsi. com/uploadedFiles/_Site_Root/Products/Literature/Application_Notes/TSI106.pdf. Accessed November 6, 2015.

46. Haugland RA, Varma M, Wymer LJ, Vesper SJ. Quantitative PCR analysis of selected Aspergillus, Penicillium and Paecilomyces species. Syst Appl Microbiol. 2004;27(2):198-210

47. Meklin T, Hauglan RA, Reponen T, Varma M, Lummus Z, Bernstein D, et al. Quantitative PCR analysis of house dust can reveal abnormal mold conditions. J Environ Monit. 2004;6(7):615-20.
48. Brinkman NE, Haugland RA, Wymer LJ, Byappanahalli M, Whitman RL, Vesper SJ. Evaluation of a rapid, quantitative real-time PCR method for enumeration of pathogenic Candida cells in water. Appl Environ Microbiol. 2003;69(3):1775-82

49. Vesper S, McKinsly C, Haugland R, Wymer L, Bradham K, Ashley P, et al. Development of an environmental relative moldiness index for US homes. J Occup Environ Med. 2007:49(8):829-33.

50. Kopp MV, Niggemann B, Forster J. House dust mite allergy: complete removal of the provoking allergen is a primary therapeutic approach. Allergy. 2009;64(9):1402-3.

\section{Submit your next manuscript to BioMed Central and we will help you at every step:}

- We accept pre-submission inquiries

- Our selector tool helps you to find the most relevant journal

- We provide round the clock customer support

- Convenient online submission

- Thorough peer review

- Inclusion in PubMed and all major indexing services

- Maximum visibility for your research

Submit your manuscript at www.biomedcentral.com/submit
C) BioMed Central 